\title{
Las variedades del español a través del doblaje cinematográfico
}

\author{
The Varieties of Spanish Through \\ Cinematographic Dubbing
}

\author{
Chiara Mazzitelli \\ Scoula Superiore per Mediatori Linguistici di Pisa \\ chiaramazzitelli994@gmail.com \\ Fuensanta Garrido Domené \\ Universidad de Córdoba (España) \\ fgdomene@uco.es
}

Resumen

El propósito de este trabajo es establecer las diferencias significativas que distinguen y caracterizan las variedades del español, analizando la riqueza y las dificultades que representan a partir del cotejo en la TAV (traducción audiovisual) y doblaje español (europeo y americano) de la película de dibujos animados Hotel Transylvania 2, en la que se dan diferencias diatópicas entre determinados personajes. Este rasgo ha permitido establecer diferencias internas y externas entre las dos versiones: la europea y, en este caso, la mexicana. Por ello, se explicarán las dificultades que presenta la labor de traducción e interpretación de las variedades de la lengua española en Europa y en Hispanoamérica, las diferencias en sus respectivos usos sintácticos, morfológicos, semánticos y léxicos, un excelente material para llevar a cabo cotejos y estudios comparativos desde el prisma de la Sociolingüística.

Palabras Clave: variedades del español, doblaje cinematográfico, sociolingüística, traducción audiovisual

\section{Abstract}

The purpose of this work is to establish the significant differences that distinguish and characterize varieties of Spanish by analyzing the richness and the difficulties that they represent by means of comparing the translation and dubbing into Spanish (European and American) of the animated film Hotel Transylvania 2, in which there are diatopic differences between certain characters. This feature allowed the establishment of internal differences in each version, as well as external differences between the two versions, the European and, in this case, the Mexican one. Therefore, we are able to explain the difficulties for translation and interpretation of these two varieties of the Spanish language spoken in Europe and in Latin America, the dif- 
ferences in their respective syntactic, morphological, semantic and lexical uses. This case study provides excellent material for carrying out comparative studies from a sociolinguistic perspective.

KeYworDS: variations of Spanish, cinematographic dubbing, Sociolinguistics, audiovisual translation

FECHA DE RECEPCIÓN: 30/08/2018

FECHA DE ACEPTACIÓN: 06/02/2019

Es un hecho incuestionable, en la actualidad, que una lengua como la española posee una rica variedad de variantes y usos dialectales. Esta obviedad, además, viene avalada por el hecho de que el español es la segunda lengua más hablada del mundo. Tal es así que sus variedades no solo quedan limitadas al ámbito geográfico peninsular (gallego, vasco, catalán, las llamadas hablas de tránsito y las hablas andaluzas), sino que se extienden a las islas (Baleares y Canarias) y a otros continentes. Dejando a un lado la variedad de español que se habla en Filipinas y en Guinea, nuestro análisis se centrará en la llamada variedad peninsular o europea, con especial atención a la variante estándar y castellana frente a las variedades habladas en el norte, centro y sur de América. Por ello, se tendrá muy presente en este trabajo el concepto de panhispanismo.

Nuestra pretensión, por tanto, es encontrar y enumerar los puntos de unión y diferenciación en las variedades hispánicas a través de un análisis del mundo de la traducción audiovisual (a partir de aquí, TAV) y doblaje cinematográfico. ${ }^{1}$ Queremos demostrar que no existe razón para que se menosprecie una va-

\footnotetext{
${ }^{1}$ Para una mayor comprensión de esta exposición, es necesaria una diferenciación entre ambos conceptos tan cercanos. La TAV se refiere al trabajo de traducir el guion de la película, mientras que el doblaje se refiere a que alguien, por lo general un actor u otra persona distinta al traductor, preste su voz a los personajes. La primera hace hincapié en las diferencias de uso gramatical, mientras que la segunda implica más las diferencias diatópicas desde el punto de vista fonético-fonológico y léxicosemántico.
} 
riedad del español — como de cualquier otro idioma- o que se defina una única modalidad como correcta y digna, dado que cada una es el resultado de una evolución social, cultural y geográfica, es decir, de la identidad propia que esta expresa.

Como ya ocurre desde hace años, las películas extranjeras se suelen traducir y doblar al español en dos o más versiones: para las diferentes variantes de español en Hispanoamérica y para el español estándar peninsular. Esto se debe a las diferencias diatópicas del español hablado que crean, por lo tanto, la necesidad de tener versiones en las que el público de diferentes hablas pueda identificarse y recibir el mensaje con inmediatez y con el matiz correcto. Tal y como lo define la Real Academia Española en su Diccionario, el doblaje es "en cine y televisión, operación en la que se sustituye la voz original de un actor por otra, en distinto idioma o en el mismo" (DLE: s.v.). Sin embargo, con la llegada de la televisión a España y debido a las malas condiciones contractuales de los actores de doblaje españoles, se recurrió, para la mayor parte de series y películas animadas (generalmente de Disney, Warner, Hanna-Barbera, Metro Goldwyn Mayer y Filmation), a las versiones de Hispanoamérica hasta principios de la década de los ochenta e incluso hasta principios de los noventa. Así las cosas, los primeros doblajes al español se realizaron en Estados Unidos, presentándose como una mezcla inusual de acentos de las distintas regiones peninsulares y de Hispanoamérica, ya que el actor de doblaje no existía aún como profesión institucionalizada y a Estados Unidos llegaban inmigrantes de diferentes partes del mundo. Esta "oralidad fingida", en palabras de Koch y Oesterreicher (2007: 20-42, especialmente 20-22), no fue bien recibida en sus orígenes, si bien es cierto que películas como Blancanieves, El libro de la Selva, Dumbo y La Cenicienta son clásicos mundialmente reconocidos; de hecho, la primera película de Disney (Blancanieves) fue rechazada por el público por la falta de uniformidad en el doblaje. Por ello, Disney decidió trasladar los estudios de doblaje a distintos países hispanoparlantes y contratar exclusivamente directores y actores de habla española. México comenzó, al inicio de la década de los años cincuenta, su industria de doblaje de producciones 
Disney. El doblaje no se permitió "hasta finales de la década de los cuarenta, en parte porque se pensaba que hacía una competencia grave al cine nacional, por lo que sólo se permitió en el caso de las películas animadas o de series infantiles" (Bravo García, 2008: 67), pero también porque no fue hasta comienzos de la década de los noventa cuando, con el estreno de La Bella $y$ la Bestia (Beauty and the Beast), Estudios Disney decidió comercializar la película en dos versiones diferentes: una para Hispanoamérica, producida en México, y otra para España. ${ }^{2}$ Esta práctica de Estudios Disney llamó la atención de los sociolingüistas, como Iglesias Gómez:

Esta práctica se mantiene en la actualidad y ha sido la precursora de la nueva tendencia a abandonar el "español neutro" como única modalidad lingüística para el doblaje de las películas Disney comercializadas en Hispanoamérica para pasar a los "doblajes localizados" en español que, como hemos visto y comentado en el capítulo anterior, incorporan acentos y elementos de humor propios del país hispanohablante en que se exhiben (2009: 53).

Sin embargo, el doblaje de los dibujos animados es mucho más esmerado que otros, ya que se dirige, en primer lugar, a un público infantil cuyo aprendizaje del idioma está todavía en una etapa delicada de desarrollo y cuya comprensión podría resultar difícil de alcanzar; y, en segundo lugar, porque han de emplearse una serie de recursos que transmitan el "habla viva", para lo que se recurre a estrategias discursivas orientadas al contacto con el interlocutor.

$\mathrm{Al}$ atender los temas de traducción y de cine, sin duda surgen muchas controversias, especialmente relacionadas con el doblaje, en cuyo ejercicio hablamos de aporte a la cultura de una sociedad, de referencias que se crean y se utilizan en un deter-

\footnotetext{
${ }^{2}$ México y Argentina son los principales países hispanoamericanos dedicados al doblaje cinematográfico en cualquiera de sus géneros, mientras que Perú lo limita a las emisiones infantiles y utiliza el subtitulado en las que no lo son (Miquel Cortés, 2005). Sobre la variación lingüística en la práctica de la doble versión española (europea y americana) del doblaje cinematográfico, véase Pons, 2011.
} 
minado idioma. Pese a ello, en vista de que un idioma se desarrolla y representa a una sociedad que, a su vez, cuenta con su propia cultura y tradición, no se debe obviar la estrecha relación que une idioma, traducción y cultura. La traducción, en general, es entonces un importante puente que confiere comunicación y conocimiento tanto cultural como lingüístico. Hurtado Albir pone de relieve lo tremendamente complicada que puede resultar la labor del traductor, afirmando que esta "es una actividad comunicativa que se efectúa entre dos culturas diferentes y, por consiguiente, el traductor ha de conocer bien ambas culturas para ser capaz de resolver los elementos culturales que, implícita o explícitamente, traslucen en los textos" (2001: 608).

Un tema de actualidad, y aún más debatido y criticado, ha sido el "redoblaje" de filmes animados, como La Sirenita, película que se estrenó en España en 1989 con el doblaje hispanoamericano. Sucesivamente, en 1992, se empezaron a doblar películas Disney al español peninsular y, en 1998, se tomó la decisión tan desconcertante de redoblar para y en España. ${ }^{3} \mathrm{La}$ reacción del público fue inmediata: una versión que apostaba por ser neutra y que sonase más natural y agradable a los espectadores de España fue, en cambio, percibida como una torpe y ridícula imitación de la original, una caricatura. Por todo lo dicho se puede deducir que, a pesar de que se considere mejor o peor versión en sí, el doblaje debe tener una aceptación del público que, a veces, depende no solo de su crítica en el seno de la lingüística, sino más bien de su psicología y sus emociones.

Las frases se localizan para que provoquen una reacción específica - por ejemplo, la risa - en el público al que se destina $y$, sin embargo, hay ocasiones en que la adaptación no resulta como tal. Podrá, así pues, criticarse de cada TAV los fallos, erratas o traducciones inapropiadas respecto del original, mientras que, dentro del contexto de cada versión para diferentes variedades de una misma lengua, no se podrá establecer cuál es la más correcta, sino, más bien, la que tuvo mayor éxito ante su público y su país de estreno.

\footnotetext{
${ }^{3}$ Para toda la información relacionada con los sucesivos doblajes del hoy ya clásico Disney La Sirenita, consúltese <http://goo.gl/iTymfL $>$.
} 
Habida cuenta de lo comentado hasta ahora, hay que tener presente algo que existe más allá de la variedad lingüística como tal: el concepto de "cultura". El idioma es, grosso modo, compartido por diferentes poblaciones y, como consecuencia, la diversidad cultural es aún más extensa que la lingüística. Aquí radica el concepto antropológico de cultura, la diversidad de modos de comportamiento, de maneras de ver el mundo y de entender la vida, diferentes costumbres y diferentes creencias, diferentes maneras de comunicarnos y, cómo no, la existencia de diferentes lenguas. La diversidad cultural ha sido objeto de investigación de muchos antropólogos, dando lugar a múltiples definiciones o concepciones (Kahn, 1975). Así, por ejemplo, mientras que para Boas "la cultura incluye todas las manifestaciones de los hábitos sociales de una comunidad, las reacciones del individuo en la medida en que se ven afectadas por las costumbres del grupo en que vive y los productos de las actividades humanas en la medida en que se ven determinadas por dichas costumbres" (1930: 74), ${ }^{4}$ Harris entiende la cultura como un conjunto de "tradiciones socialmente adquiridas que aparecen de forma rudimentaria entre los mamíferos, especialmente entre los primates. Cuando los antropólogos hablan de una cultura humana normalmente se refieren al estilo de vida total, socialmente adquirido, de un grupo de personas, que incluye los modos pautados y recurrentes de pensar, sentir y actuar" (1982: 123). Que la cultura es adquirida socialmente es una idea que ya teorizó Taylor (1975 [1871]), de manera que el ser humano la adquiere en cuanto parte integrante de una sociedad. Así pues, y siguiendo el razonamiento de Taylor, no hay sociedad sin cultura ni cultura sin sociedad: "la cultura o civilización, en sentido etnográfico amplio, es aquel todo complejo que incluye el conocimiento, las creencias, el arte, la moral, el derecho, las costumbres y cualesquiera otros hábitos y capacidades adquiridos por el hombre en cuanto miembro de la sociedad" (Taylor, 1975: 29). Boas, como se ha visto, profundizó un poco más, concluyendo que la cultura es el resultado de la difusión y la transmisión de costumbres

\footnotetext{
${ }^{4}$ Ofrecemos nuestra traducción de las palabras de Boas.
} 
y hábitos. Además, este autor tradujo cuentos, poemas y discursos y afirmó que es necesario estudiar cada lengua en sus propios términos, esto es, en sus formas de expresión y de organización.

En el ámbito de las referencias culturales — sin duda una de las traducciones más desafiantes- el traductor se enfrenta a una de las búsquedas más puntillosas y a una de las elecciones más complicadas. Por lo tanto, es fundamental que el traductor no limite su conocimiento y estudio exclusivamente al lenguaje, sino que es indispensable que conozca y se empape - dicho de un modo burdo- de la cultura que rodea a los hablantes y que se halla, de una manera más o menos velada, detrás del mismo idioma. Así las cosas, los culturemas —entendidos como elementos no traducibles literalmente y asociados a una cultura determinada - necesitan de una larga $\mathrm{o}$, a veces, insuficiente paráfrasis para que se traslade o, más bien, para que se haga comprensible y comunicable su significado en otro idioma; y al ser - por definición- nociones específico-culturales de un país o de un ámbito cultural, muchos de ellos poseen una estructura semántica y pragmática compleja que no siempre puede ser traducida. Así los define, de la manera más completa posible, Molina: "un elemento verbal o paraverbal que posee una carga cultural específica en una cultura y que al entrar en contacto con otra cultura a través de la traducción puede provocar un problema de índole cultural entre los textos origen y meta" (2006: 79; cf. Margot, 1987: 99-100). Para Vermeer, el culturema consiste en "un fenómeno social de una cultura A que es considerado relevante por los miembros de esa cultura y que, cuando se compara como un fenómeno correspondiente en la cultura B, se encuentra que es específico de la cultura A" (1983: 8). ${ }^{5}$ Coincidimos, en fin, con Hurtado Albir (2001: 612; véase también 614-615) en la afirmación de que los culturemas son elementos del discurso que, por hacer referencia a algo específico de la cultura a la cual pertenecen, pueden no ser entendidos en absoluto, de forma parcial o de forma diferente, por hablan-

\footnotetext{
${ }^{5}$ Ofrecemos nuestra traducción de las palabras de Vermeer.
} 
tes o miembros que pertenecen a la cultura del texto-origen (TO). Según Newmark, los culturemas son fáciles de detectar, ya que son elementos asociados a una cultura específica y no pueden ser traducidos literalmente porque perderían su sentido o provocarían una transferencia nula o distinta al original en la cultura de llegada (2004: 70-73; Hurtado Albir, 2001: 136). ${ }^{6}$ Así pues, no cabe duda de que lo que confieren estos elementos es una enorme carga expresiva y rica en significado, similar al aporte de las figuras y frases idiomáticas o modismos en otros niveles del discurso.

Aunque paralelos a los anteriores en la consideración del texto audiovisual como un producto sujeto a las normas imperantes en una sociedad y en un espacio y tiempo determinados, existen estudios descriptivos basados en el análisis polisistémico que se centran especialmente en describir las tendencias y convenciones de las traducciones audiovisuales en un contexto socio-histórico concreto. ${ }^{7}$ Así pues, cabe resaltar en la TAV la importancia de un interés hacia diversos aspectos, como las relaciones políticas, económicas o sociológicas entre la cultura emisora y la cultura receptora, las normas e historia de la traducción audiovisual, la normalización lingüística y los libros de estilo y la recepción de las traducciones audiovisuales en las culturas meta. Dada la presencia de dos canales - visual y auditivo- a través de los cuales se transmite el mensaje, las técnicas de la TAV han de tener en cuenta la compensación entre elementos verbales y no verbales, de tal manera que tanto el doblaje como el subtitulado puedan aportar mucha información a través de técnicas para compensar elementos orales por otros escritos, y viceversa.

\footnotetext{
${ }^{6}$ Newmark (2004: 133-146) propone hasta cinco categorías o palabras "culturales": ecología; cultura material; cultura social; organizaciones, costumbres, actividades, procedimientos y conceptos; y gestos y hábitos.

${ }^{7}$ Según Martínez Garrido, se define como "que incluye los estudios sobre panoramas audiovisuales; relaciones políticas, económicas o sociológicas entre la cultura emisora y la cultura receptora; normas de traducción; recepción de la TAV en la cultura meta; historia de la TAV y estudios sobre normalización lingüística y libros de estilo" (2013: 31).
} 
Uno de los problemas de la traducción audiovisual, y concretamente del doblaje, es el tratamiento de los acentos y las variantes diatópicas representadas en el habla de los distintos personajes. La peculiaridad del texto audiovisual es el discurso hablado elaborado precedentemente como texto escrito. Este tiene una función "pública" que depende de la intención del autor y del tipo de público, pero, en última instancia, lo que se persigue es fusionar los rasgos propios de la lengua estándar y los típicos de los registros orales coloquiales que dan al texto dinamismo y autenticidad. Según la clasificación de Gregory y Carroll (1978), el discurso es escrito para ser oralizado como si no hubiera sido escrito. Lo difícil es conseguir una intersección entre los rasgos propios de la lengua estándar ${ }^{8}$ y aquellos rasgos típicos de los registros orales coloquiales que confieren al texto un tono de veracidad y agilidad (Chaume, 2004: 20). En definitiva, lo que se persigue es conseguir una coloquialidad natural, aunque es una realidad que la crítica la identifica como restringida y ficticia porque algunos de sus rasgos más característicos tienen que ser suprimidos o limitados en número o, a veces, en forma. Redundancias, digresiones, anacolutos, hipérbatos y dubitaciones cansarían y estorbarían al espectador y, además, probablemente no resultarían tan útiles para cumplir con las convenciones formales de longitud, inmediatez y relevancia lingüística establecidas en este género de texto (Chaume, 2001: 80). Por todo ello, el discurso de los textos audiovisuales se encuentra a medio camino de una escala de nivel de elaboración; "se trata, por lo tanto, de un discurso oral prefabricado, pensado, elaborado según unas convenciones determinadas, en una palabra, controlado" (Chaume, 2001: 81).

Este tipo de discurso, que ha recibido múltiples denominaciones - "oralidad fingida", "oralidad construida", "oralidad prefabricada", "oralidad ficticia”, "oralidad literaria”, "oralidad inventada", "mímesis de lo oral", entre otras - ha favorecido un empuje de "trabajos que tanto para el español actual como para

\footnotetext{
${ }^{8}$ Propio de la lengua estándar es evitar elisiones y relajaciones fonéticas, segmentación de los enunciados y elisiones de conectores.
} 
su conocimiento diacrónico, han aportado importantes resultados en el análisis de una lengua que ya no es concebida como un bloque monolítico y homogéneo, sino en la que la variación lingüística se constituye en rasgo inherente a su misma condición histórica" (Leal, 2011: 260).

En conclusión, el traductor tiene que enfrentarse no solamente con la dificultad de la traducción en sí, sino también con la de intentar unificar los registros coloquiales y los formales neutros. Por otro lado, ha de tenerse siempre en cuenta el papel aún más prominente del espectador, en cuanto a consumidor final del producto y, por lo tanto, factor de influencia primario en el éxito de un enorme equipo de trabajo dentro de una industria tan difundida como la del cine. Por otra parte, más adelante hablaremos del importante papel de los acentos, otra elección muy delicada por un traductor audiovisual. Todo ello lo aborda Leal, que lo resume de la siguiente manera:

El problema es que la solución de equivalencia es arbitraria en el sentido de que se busca entre las modalidades existentes de la lengua meta la más congruente con el personaje y/o situación comunicativa. Esta decisión implica por parte del traductor una fuerte carga de subjetividad en la que los estereotipos, con su alta dosis de simplificación de la realidad y su carácter socializador (trascienden la dimensión individual), juegan un papel clave (2011: 270).

Analizaremos, a continuación, Hotel Transylvania 2, una película animada de fantasía y comedia en formato 3D, producida por Sony Pictures Animation y que se estrenó en 2015 por Columbia Pictures. Es la segunda parte de su homónima de 2012, Hotel Transylvania. Los personajes principales aparecen doblemente caracterizados por representar cada uno un "prototipo" de monstruo (vampiro, hombre lobo, cabeza reducida, etc.) y por el acento que los doblajes peninsular y americano les otorgan. Entre las diferentes versiones realizadas en Hispanoamérica, hemos analizado el doblaje mexicano en el que, por su parte, se nota la relajación de la pronunciación de la vibrante 
(simple y múltiple) que, en cambio, es más marcada en el doblaje peninsular. Sin embargo, el acento mexicano tiene un ritmo más rápido, repleto de altibajos y una entonación más musical. La pronunciación mexicana tiende a un cierre de las vocales $(e>$ i) y presenta una debilitación de la pronunciación de la vibrante, como ya se ha indicado, y de la velar fricativa, produciendo un sonido menos gutural.

Se han presentado, de manera somera, obstáculos en la comprensión y búsqueda de términos por dificultades de audición, combinados con un léxico cuyo empleo se limita a algunos países hispanoamericanos. Sirvan de ejemplo términos como chorría por "chorrea" o locáilo por "locario", un adjetivo que, en su uso popular y/o en su jerga juvenil, se refiere a personas de poco juicio o sin sensatez, según el Diccionario de americanismos (s.v.), y que es habitual en Nicaragua, Costa Rica, Panamá, Puerto Rico, Perú y Paraguay.

Un ejemplo reciente de esta caracterización de personajes a través de los acentos se da también en la película Coco, recientemente estrenada, cuyo doblaje ha sido motivo de discusión en España. Originariamente esta película, que trata la tradicional fiesta mexicana de los muertos, llegó a España doblada al español de México, algo que no gustó a los más puristas de nuestra lengua, que la censuraron y "exigieron" una versión peninsular, perdiendo, de esta manera, la esencia de la película propiamente dicha. ${ }^{9}$

Volviendo a Hotel Transylvania 2, tras su visualización en las versiones mexicana y peninsular, hemos esbozado las principales diferencias de traducción y de doblaje, lo que ha permitido establecer unas diferencias de las variedades americana (principalmente la de México, junto a las otras destacadas) ${ }^{10}$

\footnotetext{
${ }^{9}$ El debate sobre el cambio de doblaje a un español peninsular en detrimento del original mexicano se hizo viral en las redes sociales.

${ }^{10}$ Pese a la terminología que pueda resultar genérica (español peninsular y español americano), llegado el caso se diferenciarán matices diatópicos en cada una de estas variedades. Si bien es cierto que el uso predominante de la versión peninsular es el español estándar, para determinados personajes se aplica una variedad diatópica peninsular (andaluz) y americana (cubano); de la misma manera, en la versión ame-
} 
y peninsular y proporcionar una visión holística a través de la comparación de elecciones en las dos versiones con su propio léxico, construcciones gramaticales y entonación. De este cotejo destacan ciertos rasgos diferenciales entre el doblaje mexicano y el peninsular: tras este análisis, a efectos verbales queda confirmada la preferencia en la versión mexicana del uso del indicativo que, en cambio, se corresponde a un subjuntivo, la mayoría de las veces, en la versión peninsular. Además de mayor presencia de expresiones con infinitivo en la versión mexicana, este gusto mexicano por las perífrasis durativas con gerundio en lugar de presente de indicativo se debe, con toda probabilidad, por influencia del doblaje original en inglés, pero también por ser un uso más frecuente en las variedades del español en América. Asimismo, como en toda Hispanoamérica, el empleo del pretérito perfecto compuesto es escasísimo. De hecho, el doblaje mexicano no aporta ejemplos en dicho tiempo verbal, de manera que toda expresión que en la versión española se da en pretérito perfecto compuesto corresponderá a una oración en pretérito perfecto simple en la versión mexicana.

El uso pronominal también es un rasgo diferenciador y, por tanto, digno de tener en cuenta en cotejos de este tipo. En este sentido, pues, los pronombres tú y vosotros europeos corresponden siempre a usted y a ustedes, que no se utilizan como forma de respeto y alejamiento hacia el oyente, sino que conllevan cariño o informalidad e incluso confianza hacia el interlocutor. En la versión mexicana, además, aparecen fenómenos de laísmo, un rasgo puesto en paralelo con el leísmo de la versión peninsular. No obstante, este rasgo del español peninsular es facultativo, pues si bien está muy extendido a lo largo de toda la película, hay casos en los que no se da.

Otros rasgos, como los usos conjuntivos o de locuciones conjuntivas, adverbiales y de formación léxica, marcan también diferencias entre una y otra versión. La forma de comparación

ricana, aunque la variedad predominante es la de México, a ciertos personajes se les asignan otras variedades tanto peninsulares como americanas. 
igual ( $a$, que) se prefiere a como de la versión peninsular; incluso sustituye a también. Como en algunas zonas meridionales de España y de las islas Canarias, el adverbio acá se prefiere a aquí. En cuanto a la derivación, es bien sabido que la de México es una de las variedades de español de América en la que más destacan los diminutivos en -ito/a, no solo como manifestación de cariño, sino como vocablos en sí de uso diario, como sucede también en muchas otras variedades.

Desde el punto de vista lexical, la expresión peninsular y coloquial guay - aparte de algunos casos, dependiendo del contexto- siempre corresponde a cool, un préstamo del inglés que ya ha entrado a formar parte del vocabulario diario en muchísimos países de Hispanoamérica como forma alternativa o intercambiable con otras expresiones lugareñas (chido o padre en México, chevere o bacán en Ecuador o bárbaro en Argentina, por ejemplo). De la misma manera, la expresión wow es muy frecuente en la versión mexicana, mientras que en la peninsular aparece solamente una vez; el resto se tradujo con expresiones alterativas al préstamo. Lo mismo sucede con $o k$. Por otra parte, el verbo chequear de la versión mexicana se repite muchas veces y se utiliza en distintos contextos en su correlato europeo. Lo mismo ocurre con el sustantivo nene/a, muy empleado en la versión mexicana, en lugar de chico/a, hijo/a, querido/a de la peninsular. Hemos identificado, asimismo, diferencias léxicas en expresiones de (des)cortesía y/o afectivas. Piénsese, a este respecto, en la designación viejo, que en México aparece recogida, según los manuales consultados, como tratamiento afectivo, frente a la connotación despectiva que tiene en el español peninsular, razón por la cual este tipo de expresión solo aparece en la versión para México. Asimismo, hemos identificado ciertos marinerismos en el verbo amarrar, en la versión mexicana, empleado por atar, en la europea, lo que evidencia la supuesta influencia del léxico de los marineros que arribaron a las Américas en el período colonial.

El siguiente cuadro muestra, de manera gráfica y ejemplar, todo lo destacado en nuestro análisis comparativo: 
Las variedades del español a través del doblaje cinematográfico

\begin{tabular}{|c|c|c|}
\hline RASGO & Español dE MÉXICO & ESPAÑOL PENINSULAR \\
\hline $\begin{array}{l}\text { Usos modales } \\
\text { de los verbos }\end{array}$ & $\begin{array}{l}\text { Tal vez sí, a veces lo dices } \\
\text { Si todos estamos unidos } \\
\text { seremos felices }\end{array}$ & $\begin{array}{l}\text { Quizás lo digas a veces } \\
\text { Mientras estemos todos } \\
\text { iuntos seremos felices }\end{array}$ \\
\hline $\begin{array}{l}\text { Usos temporales } \\
\text { de los verbos }\end{array}$ & $\begin{array}{l}\text { ¡Fuiste tú! } \\
\text { Ya me respondió } \\
\text { Estuve pensando }\end{array}$ & $\begin{array}{l}\text { ¡Has sido tú! } \\
\text { Ya ha contestado } \\
\text { He pensado }\end{array}$ \\
\hline $\begin{array}{l}\text { Infinitivo } \\
\text { vs. } \\
\text { indicativo }\end{array}$ & $\begin{array}{l}\text { ¿Cómo saberlo? } \\
\text { Para que practiques cómo } \\
\text { responder }\end{array}$ & $\begin{array}{l}\text { ¿Y cómo lo sabes? } \\
\text { Para que practiques } \\
\text { y le respondas }\end{array}$ \\
\hline $\begin{array}{l}\text { Perífrasis verbales } \\
\text { vs. indicativo }\end{array}$ & $\begin{array}{l}\text { ¿Por qué estoy flotando? } \\
\text { ¿Qué le está pasando? } \\
\text { ¿Qué está haciendo él aquí? }\end{array}$ & $\begin{array}{l}\text { ¿Por qué floto? } \\
\text { ¿Qué le pasa? } \\
\text { ¿Y este qué hace aquí? }\end{array}$ \\
\hline $\begin{array}{l}\text { Pronombres } \\
\text { personales }\end{array}$ & $\begin{array}{l}\text { Recuerden } \\
\text { Ustedes son mi familia } \\
\text { ¿Mirenme, no están viendo! }\end{array}$ & $\begin{array}{l}\text { Recordad } \\
\text { Sois mi familia } \\
\text { ¡Miradme, no miráis! }\end{array}$ \\
\hline Leísmo & $\begin{array}{l}\text { No lo fuerces } \\
\text { ¿Lo quieres saludar? }\end{array}$ & $\begin{array}{l}\text { No le fuerces } \\
\text { ¿Quieres verle? }\end{array}$ \\
\hline Laísmo & Contéstala & Contéstale \\
\hline $\begin{array}{l}\text { Conjunciones y } \\
\text { adverbios }\end{array}$ & $\begin{array}{l}\text { Yo igual te quiero } \\
\text { Acá }\end{array}$ & $\begin{array}{l}\text { Yo también te quiero } \\
\text { Aquí }\end{array}$ \\
\hline Usos de diminutivos & $\begin{array}{l}\text { Chamaquita } \\
\text { Hijito } \\
\text { Chiquito, a la camita }\end{array}$ & \\
\hline
\end{tabular}




\begin{tabular}{|c|c|c|}
\hline RASGO & EsPAÑol dE MÉXICO & ESPAÑOL PENINSULAR \\
\hline Léxico & $\begin{array}{l}\text { ANGLICISMOS } \\
\text { Cool } \\
\text { Wow! } \\
\text { Ok } \\
\text { Chequear } \\
\text { Cayke } \\
\text { Slurpy } \\
\text { EXPRESIONES DE } \\
\text { (DES)CORTESIA Y } \\
\text { AFECTIVAS } \\
\text { Trasero } \\
\text { Papá, quiero cargar } \\
\text { a mi bebé } \\
\text { Tómalo } \\
\text { Viejo } \\
\text { Nene/a } \\
\text { MARINERISMOS } \\
\text { Amarrar }\end{array}$ & $\begin{array}{l}\text { Guay } \\
\text { ¡Hala! } \\
\text { Vale } \\
\text { Controlar, comprobar, intentar } \\
\text { Pastelín } \\
\text { Granizado } \\
\text { EXPRESIONES DE (DES)CORTESIA Y } \\
\text { AFECTIVAS } \\
\text { Culo } \\
\text { Papá, ¿puedo coger a mi bebé? } \\
\text { Cógelo } \\
\text { Viejo } \\
\text { Chico/a, hijo/a, querido/a } \\
\text { MARINERISMOS } \\
\text { Atar }\end{array}$ \\
\hline
\end{tabular}

Como ya se anunció más arriba, el doblaje español otorga a ciertos personajes acentos diferentes. De ellos, destacan los siguientes: Drac, el vampiro de Transylvania, tiene acento rumano, mientras que la familia de lobos presenta la variante diatópica andaluza; algunos personajes tienen acento mexicano que marcan también con términos muy conocidos, lo que permite reconocer enseguida la variación de español que se quiere poner de relieve (papi, pendejo, ahorita, etc.). Se elige, además, el acento argentino para un personaje que tiene que resultar raro y diferente a los demás (¿qué decís?, voseo; tomátela, con desplazamiento acentual), los personajes de los turistas en coche tienen acento francés en la versión peninsular, pero no en la mexicana $\mathrm{y}$, frente a la versión mexicana, la europea presenta el fenómeno del yeísmo, común en prácticamente toda España.

Así las cosas, destaca el papel de los acentos según los personajes, con lo que se consigue no solo diferenciar un personaje de otro por su origen (Drac, los turistas, etc.), sino también otorgar a cada uno un rasgo y unos modismos que hacen que su personaje llegue al público tal y como es. Por ejemplo, la familia de lobos son personajes bastante chistosos y divertidos, 
muy peculiares y extravagantes, por eso en la versión peninsular se decide darle un acento que marque estas características casi folcloristas, que en España se identifican tradicionalmente con las de los andaluces. Los rasgos propios de las hablas andaluzas que presenta esta peculiar familia, y que permiten al espectador reconocer esta variedad diatópica sin problema, son principalmente fónicos y léxicos: el término chuche por "caramelo", curro por "trabajo" (empleado en toda España, pero especialmente en Andalucía), síncopas de consonantes o grupos consonánticos (especialmente de la $d$ intervocálica), aspiración de la sibilante implosiva y final que provoca mayor apertura de la vocal precedente o silábicos ( $p a$ má por "para más"), asimilaciones de fonemas (et'to por "esto") y tendencia a pronunciar de manera muy relajada las consonantes finales, llegando, a veces, a desaparecer (mujé por "mujer").

Esta peculiaridad de las diferencias diatópicas en una película animada para niños no es la primera en la historia de este tipo de largometrajes. En Dumbo y en El libro de la selva, por ejemplo, también se recurre a las marcas dialectales: Dumbo y Timothy se encuentran con los cuervos que enseñan al elefantito a volar, mientras que Mowgli tiene cuatros buitres que intentan animarlo porque se siente solo y abandonado. Estos filmes, junto a otros clásicos Disney, fueron analizados por Leal, quien vio que lo que tienen en común los protagonistas de estas películas es la decepción que los lleva a huir de lo que es la normalidad, la sociedad, encontrando a "personajes marginales representados por pájaros (cuervos, buitres) que tratan de devolverles la confianza a partir de comentarios de carácter cómico" (Leal, 2011: 269-270). En este sentido, hace hincapié en la caracterización de los personajes a través de los acentos, con particular atención al andaluz:

A este efecto cómico contribuye sin duda la presencia de variedades dialectales marcadas. Así, el plumaje negro de los cuervos y su organización en una especie de "banda" pudo favorecer que su discurso en la lengua original acogiera rasgos de habla estereotípicos afroamericanos. Por su lado, en El libro de la selva aparecen cua- 
tro buitres que se expresan con marcado acento británico [...]. Así, los cuervos de Dumbo en el doblaje analizado se expresan con un acento español diferente: el cuervo predicador y el de gafas hablan con un acento próximo a la variante no marcada habitual en estos doblajes, el cuervo del sombrero de paja con un acento cubano, y el cuervo gordo con acento mejicano. La modalidad andaluza se hace presente en boca del cuervo Jim, el jefe de la pandilla, doblado por Florencio Castelló, el mismo actor que puso acento andaluz al buitre Despeinao de El libro de la selva (Leal, 2011:270).

En definitiva, creemos que, como la gran mayoría de los dibujos animados contemporáneos, la nueva tendencia en las películas animadas se diferencia mucho de las primeras destinadas a un público infantil, como los clásicos Disney, por ejemplo. El léxico y las expresiones ya no son ficticias, inusuales y pensadas específicamente para los niños, sino que emplean, sin problemas, expresiones coloquiales y corrientes, así como muchos chistes con juegos de palabras o referencias de cultura general que los niños no pueden entender. Se incorporan fácilmente temas modernos, actuales y fraseología de jerga juvenil o tecnológica. Es casi como si la industria del cine ya no quisiera crear un mundo "demasiado" encantado para los niños, sino más bien proporcionarles un medio diferente, más concreto y certero de conocer y acercarse a la realidad.

Bibliografía

Asociación de Academias de la Lengua Española, Diccionario de americanismos, <https://goo.gl/xTiRyJ> [consultado el 20 de febrero de 2018].

BoAs, F. (1930), "Anthropology", en Encyclopedia of the Social Sciences, vol. 2, Nueva York, Macmillan, pp. 73-110, $<$ https://goo.gl/pkthT5> [consultado el 24 de mayo de 2018].

Bravo García, E. M. (2008), El español internacional: conceptos, contextos y aplicaciones, Madrid, Arco/Libros. 
Chaume, F. (2001), "La pretendida oralidad de los textos audiovisuales y sus implicaciones en traducción", en F. Chaume y R. Agost (eds.), La traducción de los medios audiovisuales, Castellón, Universitat Jaume I, pp. 77-90.

Chaume, F. (2004), Cine y traducción, Madrid, Cátedra.

Gregory, M. y S. CARroll (1978), Language and situation: Language varieties and their social contexts, Londres, Routledge / Kegan Paul.

HARRIS, M. (1982), Introducción a la antropología general, Madrid, Alianza Editorial.

Hurtado Albir, A. (2001), Traducción y traductología. Introducción a la traductología, Madrid, Cátedra.

Iglesias Gómez, L. A. (2009), Los doblajes en español de los clásicos Disney, tesis doctoral, Salamanca, Universidad de Salamanca, <http://goo.gl/6QvSC4> [consultado el 1 de abril de 2018].

KAHN, J. S. (1975), El concepto de cultura: textos fundamentales, Barcelona, Anagrama.

Koch, P. y W. Oesterreicher (2007), La lengua hablada en la Romania: español, francés, italiano, Madrid, Gredos.

LEAL Abad, E. (2011), "La oralidad fingida en la animación infantil: la deducción de la cota de la variación lingüística y la explotación discursiva de las variedades dialectales", en J. J. de Bustos Tovar, R. Cano Aguilar, E. Méndez García de Paredes y A. López Serena (coords.), Sintaxis y análisis del discurso hablado en español: homenaje a Antonio Narbona, vol. 1, Sevilla, Universidad de Sevilla, pp. 259-274.

Margot, J. C. (1987), Traducir sin traicionar, Madrid, Ediciones Cristiandad.

Martínez Garrido, G. (2013), Estudio descriptivo y contrastivo de la traducción de elementos culturales en la subtitulación (catalán-inglés), tesis doctoral, Kent, University of Kent, $<$ https://kar.kent.ac.uk/43569/> [consultado el 14 de mayo de 2018].

Miquel CoRtés, C. (2005), “Traducción y (auto)censura: el caso de Kill Bill en España y Latinoamérica”, en Jornades de Foment de la Investigació, Castellón, Universitat Jaume I, 
pp. 1-19, <http://hdl.handle.net/10234/79106> [consultado el 15 de julio de 2018].

Molina Martínez, L. (2006), El otoño del pingüino: análisis descriptivo de la traducción de los culturemas, Castellón, Universitat Jaume I.

Newmark, P. (2004), Manual de traducción (versión en español de Virgilio Moya), Madrid, Cátedra.

Pons Rodríguez, L. (2011), "Español de España y español de América en el doblaje: la variación lingüística a través de un estudio de caso", en D. M. Sáez Rivera et al. (eds.), Últimas tendencias en traducción e interpretación, Madrid / Fráncfort, Iberoamericana / Vervuert, pp. 59-78.

Real Academia de la Lengua Española, Diccionario de la lengua española, <https://dle.rae.es/> [consultado el 12 de enero de 2018].

TAYlor, E. B. (1975 [1871]), "La ciencia de la cultura", en J. S. Kahn (comp.), El concepto de cultura: textos fundamentales, Barcelona, Anagrama, pp. 29-46.

VERMeER, H. J. (1983), "Translation theory and linguistics", en P. Roinila, R. Orfanos y S. Tirkkonen-Condit (eds.), Näkökohtia kääntämisen tutkimuksesta, Joensuu, Joensuu University, pp. 1-10.

\section{Chiara Mazzitelli}

Es licenciada en Traducción e Interpretación. Estudió en Córdoba durante su último año de la carrera, donde su profesora Fuensanta Garrido Domené se convirtió en subdirectora del Trabajo de Fin de Grado titulado Interlingüistica y sociología: El español en América y en España a través del doblaje de Hotel Transylvania 2.

Actualmente sigue colaborando con Fuensanta Garrido Domené para proyectos de traducción y lingüística. 


\section{Fuensanta Garrido Domené}

Es doctora en Filología Clásica (Griego) y profesora en la Universidad de Córdoba. Durante casi una década fue profesora de Lengua Española en la Universidad de Huelva, donde impartió muy diversas asignaturas relacionadas con esta área y publicó trabajos relacionados con la Lengua Española, su historia, evolución y didáctica. Sus primeros años en la Universidad de Córdoba también estuvieron dedicados a la enseñanza de la Lengua Española, con asignaturas como Variación Lingüística, Sociolingüística y Pragmática, entre otras. 